\title{
Factors associated with low birthweight in term pregnancies: a matched case-control study from rural Pakistan
}

Muhammad A. Habib ${ }^{1,2}$, Camille R. Greenow ${ }^{3}$, Shabina Ariff ${ }^{2}$, Sajid Soofi ${ }^{2}$, Abid Hussain $^{2}$, Qamar Junejo ${ }^{2}$, Amjad Hussain $^{2}$, Fariha Shaheen ${ }^{2}$ and Kirsten I. Black ${ }^{1}$

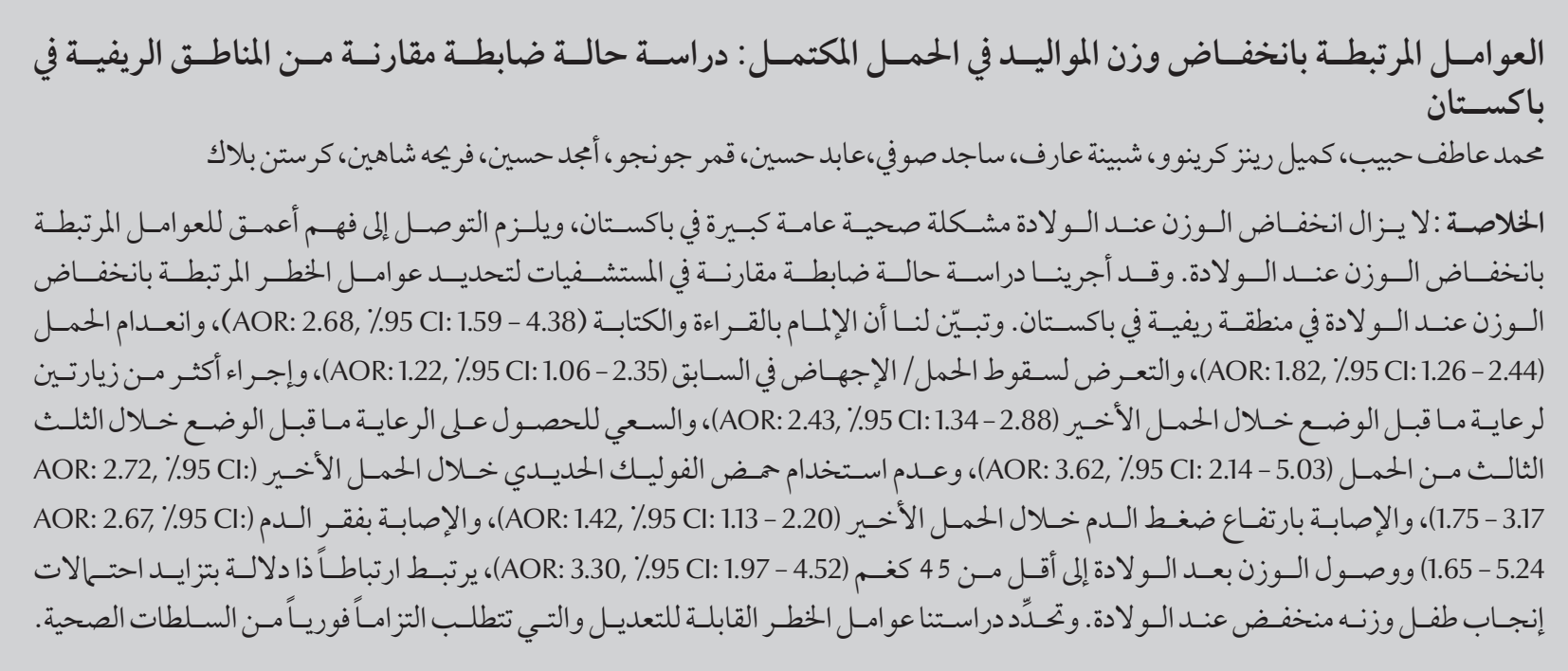

ABSTRACT Low birthweight (LBW) remains a significant public health problem in Pakistan and further understanding of factors associated with LBW is required. We conducted a hospital-based matched case control study to identify risk factors associated with LBW in a rural district of Pakistan. We found that illiteracy (AOR: 2.68; 95\% Cl: 1.59 - 4.38), nulliparity (AOR: 1.82; 95\% Cl: 1.26-2.44), having a previous miscarriage/abortion (AOR: 1.22; 95\% Cl: 1.06-2.35), having < 2 antenatal care (ANC) visits during last pregnancy (AOR: 2.43; 95\% Cl: 1.34-2.88), seeking ANC in third trimester (AOR: 3.62; 95\% Cl : 2.14-5.03), non-use of iron folic acid during last pregnancy (AOR: 2.72; 95\% Cl: 1.75-3.17), having hypertension during last pregnancy (AOR: 1.42; 95\% Cl: 1.13-2.20), being anemic (AOR: 2.67; 95\% Cl: 1.65-5.24) and having postpartum weight of $<45 \mathrm{~kg}$ (AOR: 3.30; 95\% Cl : 1.97-4.52) were significantly associated with an increased odds of having a LBW baby. Our study identifies modifiable risk factors requiring immediate commitment from the health authorities.

Facteurs associés à une insuffisance pondérale à la naissance dans les cas de grossesses à terme : étude castémoins appariés au Pakistan rural

RÉSUMÉ L'insuffisance pondérale à la naissance demeure un problème de santé publique significatif au Pakistan, et une compréhension approfondie des facteurs associés à ce problème est requise. Nous avons conduit une étude cas-témoins appariés en hôpital afin d'identifier les facteurs de risque associés à l'insuffisance pondérale à la naissance dans un district rural du Pakistan. Il est apparu que l'analphabétisme (OR ajusté : 2,68 ; IC de $95 \%$ : 1,59-4,38), la nulliparité (OR ajusté : 1,82 ; IC de $95 \%: 1,26-2,44$ ), les antécédents de fausse couche ou d'avortement (OR ajusté : 1,22; IC de $95 \%: 1,06-2,35$ ), le fait d'avoir eu moins de deux visites de soins prénatals au cours de la dernière grossesse, (OR ajusté : 2,43; IC de 95\% : 1,34-2,88), de n'avoir recherché des soins prénatals qu'au troisième trimestre (OR ajusté : 3,62; IC de 95\%:2,14-5,03), de ne pas avoir bénéficié d'une supplémentation en fer et en acide folique pendant la dernière grossesse (OR ajusté : 2,72 ; IC de $95 \%$ : 1,75-3,17), d'avoir souffert d'hypertension durant la dernière grossesse (OR ajusté : 1,42 ; IC de 95 \% :1,13-2,20), d'anémie (OR ajusté : 2,67; IC de $95 \%$ : 1,65-5,24) et d'avoir un poids post-partum de moins de $45 \mathrm{~kg}$ (OR ajusté : 3,30 ; IC de 95\% :1,97-4,52) étaient significativement associés à des risques accrus d'avoir un bébé souffrant d'une insuffisance pondérale à la naisance. La présente étude a identifié les facteurs de risque modifiables nécessitant un engagement immédiat des autorités sanitaires.

'Department of Obstetrics, Gynecology and Neonatology, Central Clinical School, University of Sydney, Sydney, NSW, Australia (Correspondence to:M.A. Habib: atif.habib@aku.edu; habibatif@yahoo.com), ²Women and Child Health Division, Aga Khan University, Karachi, Pakistan. ${ }^{3}$ Sydney School of Public Health, University of Sydney, Sydney, NSW, Australia.

Received: 06/12/16; accepted: 30/01/17 


\section{Introduction}

Low birthweight (LBW) is defined as $<2500 \mathrm{~g}(1)$ and remains a significant public health problem in developing countries like Pakistan $(2,3)$. The prevalence of LBW is estimated to be $16 \%$ worldwide, $19 \%$ in the least developed and developing countries, and $7 \%$ in developed countries (4). LBW is well documented as a leading cause of neonatal morbidity and mortality and the long-term consequences include nutritional and developmental deficiencies $(5,6)$. LBW may result from preterm birth or intrauterine growth restriction (1). In developing countries in Asia intrauterine growth restriction is the main cause $(2,3)$ and is influenced by socioeconomic and maternal factors before and during pregnancy (7).

Pakistan has one of the highest global burdens of LBW, ranging from 19\% in urban areas to $32 \%$ in rural areas (8). These high rates contribute towards both the high neonatal mortality and the high stunting rates in children aged $<5$ years, which are estimated to be 58 per 1000 live births (8) and 44\% (9), respectively. LBW due to its adverse health consequences played a key role in hindering Pakistan's progress towards achievement of the Millennium Development Goal 4 (10) and is likely to affect its ability to achieve the Sustainable Development Goals related to health and nutrition. In Pakistan the data on risk factors associated with LBW in term babies are scarce, especially for rural settings. The few studies that have been conducted were either limited to urban settings or used crosssectional data (11-13).

Given that LBW exerts such a high burden of morbidity and mortality further understanding of the associated risk factors is required. The aims of this study were (1) to identify risk factors associated with LBW in term babies in a rural district of Pakistan; and (2) to inform the development of interventions aimed at modifying behaviour and other risk factors for LBW.

\section{Methods}

\section{Study design and site}

This study was a retrospective, hospitalbased, matched case-control study in a rural district of Pakistan. The data were collected between August 2014 and September 2015 from a secondary care hospital (known as THQ KN Shah) located in Taluka (subdistrict) KN Shah of Dadu; a rural district in Sindh Province. This is a 20-bed public hospital with an average of 200 births per month. The hospital has a catchment area of $\sim 150000$ people. The usual length of stay for women at the hospital is about 1 day postpartum.

\section{Sample size}

We determined the sample size using the proportion difference approach assuming a confidence level of $95 \%$, power of $80 \%$, case to control ration of 1: 1 , detectable odds ratio (OR) of 1.5 and 20\% exposure in the control group. A total sample size of 950 (475 cases and 475 controls) was achieved.

\section{Cases and controls}

We defined cases as the mothers delivering a live-born singleton baby at term with birthweight $<2500 \mathrm{~g}$ and controls as mothers delivering live-born singleton term baby weighing $2500-4000 \mathrm{~g}$. We excluded babies weighing $>4000$ g, those with congenital anomalies, multiple births and preterm births. We matched the cases and controls on the basis of neonatal sex and maternal age on the same day when cases were identified. In the event that there were $>2$ eligible controls, 1 was selected randomly.

\section{Data collection}

We used a structured and pretested data collection form that was translated into the local language. The data collection from eligible mothers was completed within 24 hours of birth. The data collection form had sections on sociodemographic status and medical and reproductive history of the women. Some data were extracted from the antenatal care (ANC) cards and transcribed onto the data collection form. After completion of the data collection form, the female medical officer also documented women's postpartum weight with the use of Seca weighing scales. For each woman, 3 readings were taken and the mean weight in kilograms was recorded. The female medical officer also recorded the weight of the neonates soon after birth using Tanita 1584 electronic baby weighing scales. After 3 readings the mean weight in grams was recorded.

\section{Explanatory variables}

The explanatory variables comprised sociodemographic and maternal variables (Table 1). The sociodemographic variables included address of residence and socio-economic status; the latter derived from household assets and utilities score using standard demographic health survey questions. The wealth quintiles were divided into five categories (poorest, poorer, middle, richer and richest). For maternal factors, we collected data on age, education, past reproductive history and information related to the last pregnancy. We recorded age in years, categorized as $<20,20-30$ and $>30$. For maternal education we collected information on number of years of completed schooling and categorized as illiterate (no formal education), primary or less ( $1-5$ years), middle ( $6-8$ years), matric ( $9-10$ years) and intermediate and above (> 10 years). We collected information on parity, defined as the number of previous births and categorized as nulliparous (0), primiparous (1), multiparous $(2-4)$, grand multiparous $(\geq 5)$.

We also collected information on the history of miscarriage, abortion and stillbirth. We sought information about the last pregnancy around the number 


\begin{tabular}{|c|c|}
\hline Variables & Description \\
\hline Socioeconomic status of the household & $\begin{array}{l}\text { Measured as quintiles of a linear index derived from household assets and } \\
\text { utilities score; wealth quintiles were divided into } 5 \text { (poorest, poorer, middle, } \\
\text { richer and richest) }\end{array}$ \\
\hline Maternal age & Categorized as $<20,20-30$ and $>30 \mathrm{yr}$ \\
\hline Maternal education & $\begin{array}{l}\text { Years of education completed and categorized as illiterate (no formal } \\
\text { education), primary or less (1-5), middle (6-8), matric (9-10) and intermediate } \\
\text { and above }(>10)\end{array}$ \\
\hline Parity & $\begin{array}{l}\text { Number of previous births and categorized as nulliparous (0), primiparous (1), } \\
\text { multiparous ( } 2-4) \text {, grand multiparous }(\geq 5)\end{array}$ \\
\hline History of miscarriage/abortion & $\begin{array}{l}\text { History of miscarriage (involuntary loss) or abortion (voluntary loss) and } \\
\text { characterized as } 1 \text { for Yes and } 2 \text { for No }\end{array}$ \\
\hline History of stillbirth & $\begin{array}{l}\text { History of stillbirth (birth to a child that showed no signs of life) and } \\
\text { categorized as } 1 \text { for Yes and } 2 \text { for No }\end{array}$ \\
\hline Number of ANC visits & $\begin{array}{l}\text { Number of ANC visits during last pregnancy and categorized as }<2,2 \text { or } 3 \text {, and } \\
\geq 4\end{array}$ \\
\hline Time when ANC was sought & $\begin{array}{l}\text { Time of pregnancy when } 1^{\text {st }} \text { ANC was sought and categorized as } 1 \text { for } 3^{\text {rd }}, 2 \text { for } \\
2^{\text {nd }} \text { and } 3 \text { for } 1^{\text {st }} \text { trimester }\end{array}$ \\
\hline Iron folic acid supplementation & $\begin{array}{l}\text { Iron folic acid supplementation during pregnancy and categorized as } 1 \text { for Yes } \\
\text { and } 2 \text { for No }\end{array}$ \\
\hline Calcium supplementation & $\begin{array}{l}\text { Calcium supplementation during pregnancy and categorized as } 1 \text { for Yes and } 2 \\
\text { for No }\end{array}$ \\
\hline History of hypertension during pregnancy & Hypertension during pregnancy and categorized as 1 for Yes and 2 for No \\
\hline History of gestational diabetes & Diabetes during pregnancy and categorized as 1 for Yes and 2 for No \\
\hline Anaemia during pregnancy & Haemoglobin concentration $<110 \mathrm{~g} / \mathrm{L}$ in whole blood \\
\hline Postpartum maternal weight & Categorized as $<45,45-55$ and $>55 \mathrm{~kg}$. \\
\hline
\end{tabular}

$A N C=$ antenatal care.

and timing of the ANC visits; the latter grouped into the following categories $<2,2-4$ and $>4$ visits. The timing of the first ANC visit was documented as having occurs in the 1st, 2nd or 3rd trimester. We also collected the data on the use of iron and folic acid supplementation, calcium supplementation, any history of hypertension and any history of diabetes. The haemoglobin status of the women measured at 1 st ANC encounter was also recorded as either anaemic $(<110 \mathrm{~g} / \mathrm{dL})$ or nonanaemic $(\geq 110 \mathrm{~g} / \mathrm{dL})$. We also measured the postpartum weight of the women, using as proxy for maternal body mass index (BMI) and categorized weight as $<45$, $45-55$ and $>55 \mathrm{~kg}$.

\section{Data management and statistical analysis}

The female medical officer checked the questionnaires for completeness and consistency and coded them before data entry. The Data Management Unit of Aga Khan University, Karachi, Pakistan, entered the data on predesigned data entry screens on Visual Fox Pro software. All data were analysed using SPSS version 19 and conditional logistic regression was used for analysis. Crude and adjusted ORs were used to investigate the factors affecting the incidence of LBW, by bivariate and multiple logistic regression, respectively. We used bivariate analysis to explore the associations between independent variables and LBW, and calculated the crude ORs and confidence intervals (CIs) were calculated. The $\chi 2$ test was used to test possible bivariate associations between independent variables and LBW. Variables significant at $\mathrm{P}<$ 0.25 were considered for inclusion in the multivariate model. Based on the bivariate analysis and a priori information, a multiple logistic regression model was constructed to examine the relationship between variables and LBW. Independent associations between variables were characterized by adjusted ORs and 95\% CIs and variables with $\mathrm{P}<0.05$ were considered statistically significant.

\section{Ethical clearance}

The Ethics Review Committee of Aga Khan University granted approval for the study. The female medical officer explained the study and obtained verbal consent from all participants. The confidentiality of all participants was ensured.

\section{Results}

A total of 950 mothers, comprising 475 cases and 475 controls, were included in the study. There were no significant differences in the socioeconomic characteristics or maternal age distribution 
between the cases and controls (Table 2). However, there were differences in literacy levels, parity, and history of abortion or miscarriage and stillbirth. Cases were less likely to have attended $>4$ antenatal visits (17.9 vs 25.9 ) and to have presented later in pregnancy $(23.8 \%$ vs $15.6 \%)$. The use of calcium supplementation during the last pregnancy was low (14.8\% and $13.9 \%$ ) among the cases and controls, respectively. The use of iron and folic acid supplementation was higher in the controls (46.4\%) compared to cases $(25.7 \%)$. Anaemia status based on low haemoglobin concentration $(<110 \mathrm{~g} / \mathrm{L})$ showed that $68.3 \%$ of the cases were anaemic compared to $42.8 \%$ of the controls. About half of the cases $(52.6 \%)$ and $37.2 \%$ of the controls had a postpartum weight $<45 \mathrm{~kg}$.

Univariate analysis was performed to determine the association between maternal risk factors and LBW (Table 3). The analysis revealed that illiteracy (OR 2.9, 95\% CI 1.74-4.88), nulliparity (OR 1.77, 95\% CI 1.19-2.63), previous miscarriage or abortion (OR 1.15, 95\% CI 1.14-2.28), < 2 ANC visits during last pregnancy (OR 2.06, 95\% CI 1.45-2.92), seeking ANC in the 3rd trimester during last pregnancy (OR 3.57, 95\% CI 2.49-5.12), non-use of iron and folic acid in last pregnancy (OR 2.51, 95\% CI 1.91-3.30), hypertension during last pregnancy (OR 1.72, 95\% CI 1.22-2.42), anaemia (OR 3.28, 95\% CI 1.80-5.97) and postpartum weight $<45 \mathrm{~kg}($ OR 3.02, 95\% CI 2.0-4.57) were significantly associated with an increased risk of having an LBW infant.

In multivariable analysis all these factors remained significant ( $\mathrm{Ta}$ ble 4). Illiteracy (AOR 2.68, 95\% CI 1.59-4.38), nulliparity (AOR 1.82, 95\% CI 1.26-2.44), previous miscarriage or abortion (AOR 1.22, 95\% CI 1.06-2.35), < 2 ANC visits during last pregnancy (AOR 2.43 95\% CI 1.35 2.88), seeking ANC in third trimester during last pregnancy (AOR 3.62, 95\% CI 2.14-5.03), non-use of iron and folic acid in last pregnancy (AOR 2.72, 95\%
CI 1.75-3.17), hypertension during last pregnancy (AOR 1.42, 95\% CI 1.13-2.20), anaemia (AOR 2.67, 95\% CI 1.65-5.24) and postpartum weight $<45 \mathrm{~kg}$ (AOR 3.30,95\% CI 1.97-4.52) were significantly associated with an increased risk of having an LBW infant (Table 2).

\section{Discussion}

This study identified a range of modifiable factors related to LBW in term babies in a rural region of Pakistan. These factors included illiteracy, nulliparity, previous miscarriage or abortion, number and timing of ANC visits, lack of iron and folic acid supplementation during pregnancy, presence of hypertension or anaemia during pregnancy and postpartum maternal weight $<45$ $\mathrm{kg}$

Previous research has documented that educated women are less likely to have an LBW baby and maternal education has a $33 \%$ protective effect against LBW (14). This has been observed in similar low-resource settings such as Nepal (15) and Bangladesh (16), and in a previous study from Pakistan (17). We also found that illiteracy was associated with LBW delivery, which is likely related to reduced service utilization and less knowledge of positive health behaviour (18). Improving attendance and access to education by young girls will address this issue, although any effect will require a long lead time and long-term investment that ensures maximum enrolment and continuation of the girls in school. Increasing health literacy among illiterate women is complex and requires additional resources directed toward individual counselling (18).

We found that nulliparous mothers were more likely to deliver LBW babies compared to multiparous women. This finding is in agreement with previous meta-analyses (19) showing that nulliparous women are consistently more likely to have LBW babies compared to their multiparous and grand multiparous counterparts. Several hypotheses have been put forward to explain this association, including the biological immaturity of young mothers and maternal-fetal competition for nutrients in women still trying to achieve their own growth potential $(20,21)$. Recent estimates by the United Nations Children's Fund (UNICEF) revealed that $21 \%$ of the girls in Pakistan are married before the age of 18 years (22). Throughout the country this has changed from 16 years in 1960 to 22 years in 2015 (23) but the mean age for marriage in rural areas remains around $16-18$ years (8). Primary reasons for this early age of marriage in Pakistan are connected with tradition, social and gender inequality and lack of awareness of the harmful impact of early marriages (24). Pakistan's Child Marriage Restraint Act 1929 sets the legal age for marriage to 16 years for women and 18 years for men. While preliminary efforts are being made to increase the minimum age for women to 18 years, this has not yet been enacted (25). Greater political will and public education are required to address the issue of early marriage and childbearing, along with greater access to modern methods of contraception.

In our study, a previous history of abortion or miscarriage was significantly associated with increased odds of delivering LBW infants. This was in agreement with previous studies $(26,27)$ and a systematic review (28) that showed a significant relationship between miscarriage and abortion and LBW; the risk of LBW appears to increase with increasing number of previous abortions (29). The underlying biological mechanisms responsible for this association may be cervical insufficiency as a result of damage caused by stretching of the cervical canal through dilatation and curettage, and cervical and uterine adhesions as a result of post abortion complications $(30,31)$. Also, miscarriages can lead to cervical incompetence and uterine 


\begin{tabular}{|c|c|c|c|c|}
\hline Variables & Cases $(n)$ & $\%$ & Controls $(n)$ & $\%$ \\
\hline \multicolumn{5}{|c|}{ Socioeconomic status of the household } \\
\hline 1 Poorest & 80 & 16.8 & 78 & 16.4 \\
\hline 2 Poorer & 101 & 21.3 & 106 & 22.4 \\
\hline 3 Middle & 94 & 20 & 96 & 20.3 \\
\hline 4 Richer & 104 & 21.9 & 97 & 20.5 \\
\hline 5 Richest & 95 & 19.9 & 97 & 20.4 \\
\hline \multicolumn{5}{|l|}{ Maternal age, yr } \\
\hline$<20$ & 114 & 24 & 114 & 24 \\
\hline $20-30$ & 242 & 50.9 & 242 & 50.9 \\
\hline$>30$ & 119 & 25.1 & 119 & 25.1 \\
\hline \multicolumn{5}{|c|}{ Maternal education (years of schooling) } \\
\hline Illiterate & 297 & 62.5 & 208 & 43.8 \\
\hline Primary or less (1-5) & 77 & 16.2 & 89 & 18.7 \\
\hline Middle (6-8) & 41 & 8.6 & 79 & 16.6 \\
\hline Matric (9-10) & 35 & 7.4 & 48 & 10.2 \\
\hline Intermediate and above $(>10)$ & 25 & 5.3 & 51 & 10.7 \\
\hline \multicolumn{5}{|l|}{ Parity } \\
\hline Nulliparous & 73 & 15.3 & 50 & 10.5 \\
\hline Primiparous & 136 & 28.6 & 103 & 21.6 \\
\hline Multiparous & 266 & 56.1 & 323 & 67.9 \\
\hline \multicolumn{5}{|l|}{ History of miscarriage/abortion } \\
\hline Yes & 72 & 15.2 & 49 & 10.4 \\
\hline No & 403 & 84.2 & 426 & 89.6 \\
\hline \multicolumn{5}{|l|}{ History of stillbirth } \\
\hline Yes & 31 & 6.6 & 18 & 3.1 \\
\hline No & 93.4 & 444 & 457 & 96.9 \\
\hline \multicolumn{5}{|l|}{ Number of ANC visits } \\
\hline$<2$ & 210 & 44.3 & 149 & 31.4 \\
\hline $2-4$ & 181 & 38.2 & 203 & 42.7 \\
\hline$>4$ & 84 & 17.5 & 123 & 25.9 \\
\hline \multicolumn{5}{|l|}{ Time when ANC was sought } \\
\hline 3rd trimester & 180 & 37.8 & 74 & 15.6 \\
\hline 2nd trimester & 182 & 38.4 & 240 & 50.5 \\
\hline 1st trimester & 113 & 23.8 & 166 & 34.9 \\
\hline \multicolumn{5}{|l|}{ Iron folic acid supplementation } \\
\hline No & 353 & 74.3 & 256 & 53.6 \\
\hline Yes & 122 & 25.7 & 219 & 46.4 \\
\hline \multicolumn{5}{|l|}{ Calcium supplementation } \\
\hline No & 405 & 85.2 & 409 & 86.1 \\
\hline Yes & 70 & 14.8 & 66 & 13.9 \\
\hline \multicolumn{5}{|c|}{ History of hypertension during pregnancy } \\
\hline Yes & 102 & 21.4 & 65 & 13.7 \\
\hline No & 373 & 78.6 & 410 & 86.3 \\
\hline \multicolumn{5}{|l|}{ History of gestational diabetes } \\
\hline Yes & 27 & 5.6 & 25 & 5.2 \\
\hline No & 448 & 94.4 & 450 & 94.8 \\
\hline \multicolumn{5}{|c|}{ Anaemia during pregnancy, haemoglobin } \\
\hline Anaemia $<110 \mathrm{~g} / \mathrm{dL}$ & 324 & 68.3 & 203 & 42.8 \\
\hline Normal $\geq 110 \mathrm{~g} / \mathrm{dL}$ & 151 & 31.7 & 272 & 57.2 \\
\hline \multicolumn{5}{|l|}{ Postpartum maternal weight, $\mathrm{kg}$} \\
\hline$<45$ & 250 & 52.6 & 177 & 37.2 \\
\hline $45-55$ & 183 & 38.5 & 208 & 43.8 \\
\hline$>55$ & 42 & 8.9 & 90 & 19.0 \\
\hline
\end{tabular}




\begin{tabular}{|c|c|c|c|}
\hline Variables & OR & $95 \% \mathrm{Cl}$ & $P$ \\
\hline \multicolumn{4}{|c|}{ Socioeconomic status of the household } \\
\hline 1 Poorest & 0.89 & $0.59-1.33$ & 0.585 \\
\hline 2 Poorer & 1.04 & $0.72-1.50$ & 0.829 \\
\hline 3 Middle & 0.97 & $0.67-1.42$ & 0.885 \\
\hline 4 Richer & 0.82 & $0.56-1.20$ & 0.311 \\
\hline 5 Richest & Ref & & \\
\hline \multicolumn{4}{|c|}{ Maternal education (years of schooling) } \\
\hline Illiterate & 2.91 & $1.74-4.88$ & 0.0001 \\
\hline Primary or less (1-5) & 1.76 & $1.01-3.11$ & 0.048 \\
\hline Middle (6-8) & 1.05 & $0.57-1.94$ & 0.854 \\
\hline Matric (9-10) & 1.48 & $0.77-2.84$ & 0.229 \\
\hline Intermediate and above $(>10)$ & Ref & & \\
\hline \multicolumn{4}{|l|}{ Parity } \\
\hline Nulliparous & 1.77 & $1.19-2.63$ & 0.0045 \\
\hline Primiparous & 1.60 & $1.18-2.17$ & 0.0023 \\
\hline Multiparous & Ref & & \\
\hline \multicolumn{4}{|l|}{ History of miscarriage/abortion } \\
\hline Yes & 1.55 & $1.14-2.28$ & 0.024 \\
\hline No & Ref & & \\
\hline \multicolumn{4}{|l|}{ History of stillbirth } \\
\hline Yes & 1.77 & $0.97-3.21$ & 0.0595 \\
\hline No & Ref & & \\
\hline \multicolumn{4}{|l|}{ Number of $A N C$ visits } \\
\hline$<2$ & 2.06 & $1.45-2.92$ & $<0.0001$ \\
\hline $2-4$ & 1.3 & $0.92-1.83$ & 0.126 \\
\hline$>4$ & Ref & & \\
\hline \multicolumn{4}{|l|}{ Time when ANC was sought } \\
\hline 3rd trimester & 3.57 & $2.49-5.12$ & 0.001 \\
\hline 2nd trimester & 1.13 & $0.83-1.54$ & 0.411 \\
\hline 1st trimester & Ref & & \\
\hline \multicolumn{4}{|l|}{ Iron folic acid supplementation } \\
\hline No & 2.51 & $1.91-3.30$ & 0.0001 \\
\hline Yes & Ref & & \\
\hline \multicolumn{4}{|l|}{ Calcium supplementation } \\
\hline No & 0.93 & $0.64-1.34$ & 0.71 \\
\hline Yes & Ref & & \\
\hline \multicolumn{4}{|c|}{ History of hypertension during pregnancy } \\
\hline Yes & 1.72 & $1.22-2.42$ & 0.0017 \\
\hline No & Ref & & \\
\hline \multicolumn{4}{|l|}{ History of gestational diabetes } \\
\hline Yes & 1.08 & $0.62-1.89$ & 0.775 \\
\hline No & Ref & & \\
\hline \multicolumn{4}{|c|}{ Anaemia during pregnancy, haemoglobin } \\
\hline Anaemia $<110 \mathrm{~g} / \mathrm{L}$ & 3.28 & $1.80-5.97$ & 0.0001 \\
\hline Normal $\geq 110 \mathrm{~g} / \mathrm{dL}$ & Ref & & \\
\hline \multicolumn{4}{|l|}{ Postpartum maternal weight, $\mathrm{kg}$} \\
\hline$<45$ & 3.02 & $2.00-4.57$ & $<0.0001$ \\
\hline $45-55$ & 1.88 & $1.24-2.85$ & 0.0029 \\
\hline$>55$ & Ref & & \\
\hline
\end{tabular}

$A N C=$ antenatal care $; C I=$ confidence interval; $O R=$ odds ratio; $R e f=$ reference group . 
abnormalities resulting in intrauterine growth restriction, which subsequently causes LBW (32). In Pakistan the burden of abortion and miscarriage is high, which was reported as $12 \%$ and $1.7 \%$, respectively, in the recent Pakistan Demographic and Health Survey (PDHS) (8). Another study conducted in 2014 estimated that annually about 2.25 million abortions are conducted in Pakistan leading to a national abortion rate of 50 per 1000 women (15-49 years) (33). Averting miscarriages and abortions requires extra vigilance during ANC and greater access to more reliable contraceptive methods. However, the prevalence of using the most effective methods, including intrauterine devices and implants, is only $3 \%$ in Pakistan (8), which is well below the neighbouring countries.
Adequate and timely antenatal care is of paramount importance for pregnant women and improves pregnancy outcomes. Studies consistent with our findings from similar settings to Pakistan have demonstrated an increased risk of delivering an LBW baby with delayed initiation of ANC, with reduced ANC visits and with inadequate service provision during ANC (34-36). We reported similar results and showed

\begin{tabular}{|c|c|c|c|}
\hline Variables & AOR & $95 \% \mathrm{Cl}$ & $P$ \\
\hline \multicolumn{4}{|c|}{ Maternal education (years of schooling) } \\
\hline Illiterate & 2.68 & $1.59-4.38$ & 0.0001 \\
\hline Primary or less (1-5) & 1.70 & $1.09-2.97$ & 0.037 \\
\hline Middle (6-8) & 1.02 & $0.54-1.98$ & 0.882 \\
\hline Matric (9-10) & 1.36 & $0.68-2.56$ & 0.310 \\
\hline Intermediate and above $(>10)$ & Ref & & \\
\hline \multicolumn{4}{|l|}{ Parity } \\
\hline Nulliparous & 1.82 & $1.26-2.44$ & 0.0022 \\
\hline Primiparous & 1.42 & $1.10-1.99$ & 0.0017 \\
\hline Multiparous & Ref & & \\
\hline \multicolumn{4}{|l|}{ History of miscarriage/abortion } \\
\hline Yes & 1.22 & $1.06-2.35$ & 0.035 \\
\hline No & Ref & & \\
\hline \multicolumn{4}{|l|}{ Number of ANC visits } \\
\hline$<2$ & 2.43 & $1.34-2.88$ & 0.0001 \\
\hline $2-4$ & 1.52 & $1.21-2.76$ & 0.0001 \\
\hline$>4$ & Ref & - & - \\
\hline \multicolumn{4}{|l|}{ Time when first ANC was sought } \\
\hline 3rd trimester & 3.62 & $2.14-5.03$ & 0.001 \\
\hline 2nd trimester & 1.21 & $0.81-1.51$ & 0.490 \\
\hline 1st trimester & Ref & - & - \\
\hline \multicolumn{4}{|l|}{ Iron folic acid supplementation } \\
\hline No & 2.72 & $1.75-3.17$ & 0.0001 \\
\hline Yes & Ref & - & - \\
\hline \multicolumn{4}{|c|}{ History of hypertension during pregnancy } \\
\hline Yes & 1.42 & $1.13-2.20$ & 0.023 \\
\hline No & Ref & - & - \\
\hline \multicolumn{4}{|c|}{ Anaemia during pregnancy, haemoglobin } \\
\hline Anaemia $<110 \mathrm{~g} / \mathrm{L}$ & 2.67 & $1.65-5.24$ & 0.0001 \\
\hline Normal $\geq 110 \mathrm{~g} / \mathrm{dL}$ & Ref & - & - \\
\hline \multicolumn{4}{|l|}{ Postpartum maternal weight, $\mathrm{kg}$} \\
\hline$<45$ & 3.30 & $1.97-4.52$ & 0.0001 \\
\hline $45-55$ & 1.76 & $1.17-2.91$ & 0.0125 \\
\hline$>55$ & Ref & - & - \\
\hline
\end{tabular}

$A N C=$ antenatal care $; C I=$ confidence interval; $O R=$ odds ratio; Ref = reference group . 
that the odds of delivering an LBW baby were greater in women who had fewer than the recommended minimum 4 ANC visits and started ANC late in their pregnancy. The recent PDHS showed that $37 \%$ of pregnant women had $\geq 4$ ANC visits with a median 3.7 months duration of pregnancy at first ANC encounter. However in rural areas only $26 \% \mathrm{had} \geq 4$ ANC visits and the median gestation at booking was 4.3 months (8). Given this and the acknowledged importance of ANC it is reasonable to call for reforms to the maternal neonatal and child health policy to ensure that ANC is delivered to all pregnant women as per the WHO guidance and recommendations.

Studies have demonstrated that non-use of iron supplements and maternal anaemia during pregnancy have a negative effect on birthweight (37, 38). In our study, maternal anaemia and non-use of iron supplementation during pregnancy were independently significantly associated with increased risk of LBW. A seminal study conducted in 2001 explored the potential mechanisms of the association between anaemia and LBW and concluded that anaemia can induce maternal and fetal stress, which stimulates the release of corticotropin releasing hormone. In turn, this increases fetal cortisol production, which consequently inhibits longitudinal growth of the fetus (39). Pakistan has a high anaemia burden and use of iron supplementation among pregnant women is alarmingly low (45\%) (8). To reduce the burden of anaemia among women, efforts should be made to increase the use of iron and folic acid supplementation, and the best strategies are iron supplementation and food fortification (40).

In our study postpartum weight < $45 \mathrm{~kg}$ was significantly associated with increased odds of having an LBW baby.
We used postpartum weight to assess the status of maternal undernutrition and used it as a proxy for maternal BMI. Previous studies have also demonstrated the association between maternal underweight and LBW $(41,42)$. This results from the fact that underweight mothers tend to have gross nutritional deficiencies and lower placental weight that lead to insufficiency $(42,43)$. Recent population-based surveys in $\mathrm{Pa}$ kistan (PDHS in 2013 and National Nutrition Survey in 2011) revealed that the prevalence of underweight (BMI $<18.5$ ) in Pakistani women was 14 and $18 \%$, respectively $(8,9)$. This is a high burden that requires immediate attention and interventions for mothers, such as nutritional counselling and food supplementation during pregnancy for improved neonatal outcomes.

Similarly, hypertension was significantly associated with LBW in our study, which is supported by previous research $(44,45)$. It is believed that hypertension causes a decrease in uteroplacental blood flow, which results in LBW and other complications (46). Data from Pakistan have reported a $15 \%$ frequency of hypertensive disorders during pregnancy (47). Therefore, early detection and management of gestational hypertension is imperative. To achieve this target in Pakistan, first-line healthcare workers should be trained and encouraged to manage hypertension in community settings using the WHO recommended guidelines (48).

We used a matched case-control design to explore the risk factors for LBW, which was an acceptable design for an analytical risk factor study. However our study had some limitations. First, we used the postpartum maternal weight as a proxy indicator for maternal BMI so our finding of the association between maternal underweight and LBW should be viewed with caution. Second, this study was carried out in a rural hospital of Sindh Province, therefore, the findings cannot be generalized to the whole country. Third, the retrospective nature and use of hospital records might have introduced recall bias.

In conclusion, we identified important risk factors associated with LBW, which are all modifiable with little investment and commitment. Therefore, a holistic approach is required from government institutions, nongovernmental organizations and civil society to ensure: proper education and counselling for women; legislation for the revised age of marriage; provision of timely and adequate ANC; universal coverage of iron and folic acid supplementation during pregnancy; and an improved family planning programme with longacting reversible contraceptives as key options.

\section{Acknowledgements}

This manuscript is part of MAH's thesis to fulfil the requirement for $\mathrm{PhD}$ at the University of Sydney. We are grateful to the Women and Child Health Division, Aga Khan University for providing the support for data collection and analysis. We are also thankful to the University of Sydney for funding MAH's PhD scholarship (IPRS/APA) and CRG's funding through the National Health and Medical Research Council (NHMRC) Career Development Fellowship \#108762. We would like to thank all the participants who took part in the study, Mr. Mushtaque Mirani and Dr. Mumtaz Begum for the support in data collection, Mr. Imran Ahmed for his support in data management, and the study team for their extensive hard work.

\section{Funding: None.}

Competing interests: None declared. 
1. World Health Organization; United Nations Children's Fund. Low birth weight: country, regional and global estimates. Geneva: WHO; 2004 (http://apps.who.int/iris/handle/10665/43184, accessed 25 May 2017).

2. Qadir M, Bhutta Z. Low birth weight in developing countries. In: Kiess W, Chernausek SD, Hokken-Koelega ACS, editors. Small for gestational age. Causes and consequences Pediatr Adolesc Med. Basel: Karger; 2009;13:148-62 (http://www. karger.com/Article/Abstract/165998).

3. Black, RE. Global prevalence of small for gestational age births. In: Embleton ND, Katz J, Ziegler EE, editors. Low birthweight baby: born too soon or too small. 81st Nestlé Nutrition Institute Workshop, Magaliesburg, March-April 2014. Basel: Karger; 2015;81:1-7.

4. UNICEF data: monitoring the situation of children and women. (http://data.unicef.org/topic/nutrition/low-birthweight/, accessed 25 May 2017).

5. KramerMS, Victora CG. Low birth weight and perinatal mortality. In: Semba RD, Bloem MW, editors. Nutrition and health in developing countries. Totowa, NJ: Humana Press; 2001:57-69 (http://link.springer.com/chapter/10.1007\%2F978-1-59259225-8_3\#page-1, accessed 25 May 2017).

6. Aylward GP, Pfeiffer SI, Wright A, Verhulst SJ. Outcome studies of low birth weight infants published in the last decade: a metaanalysis. J Pediatr. 1989 Oct;115(4):515-20. PMID:2795341

7. de Bernabé JV, Soriano T, Albaladejo R, Juarranz M, Calle ME, Martínez D, et al. Risk factors for low birth weight: a review. Eur J Obstet Gynecol Reprod Biol. 2004 Sep 10;116(1):3-15. PMID:15294360

8. National Institute of Population Studies (NIPS) and ICF International. Pakistan Demographic and Health Survey 2012-13. Islamabad: NIPS and Calverton, MD: ICF International; 2013 (https://dhsprogram.com/pubs/pdf/FR290/FR290.pdf, accessed 25 May 2017).

9. Aga Khan University, Pakistan; Pakistan Medical Research Council; Nutrition Wing, Cabinet Division, Government of Pakistan; UNICEF Pakistan (https://www.humanitarianresponse. info/system/files/documents/files/59_National\%20Nutrition\%20Survey-2011.pdf, accessed 25 May 2017).

10. Ministry of Planning. Development and Reform Government of Pakistan. Pakistan millennium development goals report 2013 (http://www.pk.undp.org/content/dam/pakistan/ docs/MDGs/MDG2013Report/final\%20report.pdf, accessed 25 May 2017).

11. Janjua NZ, Delzell E, Larson RR, Meleth S, Kristensen S, Kabagambe $\mathrm{E}$, et al. Determinants of low birth weight in urban Pakistan. Public Health Nutr. 2009 Jun;12(6):789-98. PMID:18620611

12. Rizvi SA, Hatcher J, Jehan I, Qureshi R. Maternal risk factors associated with low birth weight in Karachi: a case control study. East Mediterr Health J. 2007 Nov-Dec;13(6):1343-52. PMID:18341184

13. Khan A, Nasrullah FD, Jaleel R. Frequency and risk factors of low birth weight in term pregnancy. Pak J Med Sci. 2016 JanFeb;32(1):138-42. PMID:27022362

14. Silvestrin S, Silva $\mathrm{CH}$, Hirakata VN, Goldani AA, Silveira PP, Goldani MZ. Maternal education level and low birth weight: a meta-analysis. J Pediatr (Rio J). 2013 Jul-Aug;89(4):339-45. PMID:23809705

15. Bhaskar RK, Deo KK, Neupane U, Chaudhary Bhaskar S, Yadav BK, Pokharel HP, et al. A case control study on risk factors associated with low birth weight babies in Eastern Nepal. Int J Pediatr. 2015;2015:807373. PMID:26783406
16. Matin A, Azimul SK, Matiur AKM, Shamianaz S, Shabnam JH, Islam T. Maternal socioeconomic and nutritional determinants of low birth weight in urban area of Bangladesh. J Dhaka Med Coll. 2008;17(2):83-7 (http://banglajol.info/index.php/ JDMC/article/view/6588).

17. Anjum F, Javed T, Faheem M, Ghazanfar Ali Sheikh A. Maternal risk factors associated with low birth weight: a case control study in Lahore. Ann King Edward Med Univ. 2011;17(3):1-6 (http://www.annalskemu.org/journal/index.php/annals/ article/view/338/259).

18. Chanda SK, Howlader MH, Nahar N. Educational status of the married women and their participation at household decision making in rural Bangladesh. Int J Adv Res Technol. 2012;1(6):13746 (http://adsabs.harvard.edu/abs/2012IJART...1f.137C).

19. Kozuki N, Lee AC, Silveira MF, Sania A, Vogel JP, Adair L, et al. The associations of parity and maternal age with smallfor-gestational-age, preterm, and neonatal and infant mortality: a meta-analysis. BMC Public Health. 2013;13(Suppl 3):S2. PMID:24564800

20. Aliyu MH, Jolly PE, Ehiri JE, Salihu HM. High parity and adverse birth outcomes: exploring the maze. Birth. 2005 Mar;32(1):4559. PMID:15725205

21. Bisai S, Sen A, Mahalanabis D, Datta N, Bose K. The effect of maternal age and parity on birth weight among Bengalees of Kolkata, India. Hum Ecol. 2006;14:139-43 (http://krepublishers.com/06-Special\%20Volume-Journal/JHE-00-Special\%20 Volumes/JHE-14-Eco-Cul-Nut-HIth-Dis-Web/JHE-SI-14-19139-143-Bisai-S/JHE-SI-14-19-139-143-Bisai-S-Text.pdf).

22. The state of the world's children, 2016. A fair chance for every child. New York: United Nations Children's Fund; 2016 (https://www.unicef.org/publications/files/UNICEF_ SOWC_2016.pdf, accessed 25 May 2017).

23. Sathar ZA, Kiani MF, Soomro GY. Some consequences of rising age at marriage in Pakistan. Pak Dev Rev. 1998 Winter;37(4 Part II):541-56 (http://www.pide.org.pk/pdf/PDR/1998/ Volume4/541-556.pdf).

24. UNFPA. Marrying too young. End child marriage. New York: United Nations Population Fund; 2012 (https://www.unfpa. $\mathrm{org} / \mathrm{sites} /$ default/files/pub-pdf/MarryingTooYoung.pdf, accessed 25 May 2017).

25. Mumtaz K, Warraich S, Imam S, et al. Age of marriage, a position paper. Final draft 2010. Committee for Standardization of Female Age of Marriage (https://www.scribd.com/document/162588582/Age-of-Marriage-PDF, accessed 25 May 2017).

26. Chen $\mathrm{Y}$, et al. An epidemiological survey on low birth weight infants in China and analysis of outcomes of full-term low birth weight infants. BMC Pregnancy Childbirth. 2013 Dec 26;13:242. PMID:24370213

27. Siza JE. Risk factors associated with low birth weight of neonates among pregnant women attending a referral hospital in northern Tanzania. Tanzan J Health Res. 2008 Jan;10(1):1-8. PMID:18680958

28. Shah PS, Zao J, Knowledge Synthesis Group of Determinants of preterm/LBW births. Induced termination of pregnancy and low birthweight and preterm birth: a systematic review and meta-analyses. BJOG. 2009 Oct;116(11):1425-42. PMID:19769749

29. Brown JS, Adera T, Masho SW. Previous abortion and the risk of low birth weight and preterm births. J Epidemiol Community Health. 2008 Jan;62(1):16-22. PMID:18079328 
30. Hogue CJ, Cates W Jr, Tietze C. The effects of induced abortion, on subsequent reproduction. Epidemiol Rev. 1982;4:66-94. PMID:6754410

31. Thom DH, Nelson LM, Vaughan TL. Spontaneous abortion and subsequent adverse birth outcomes. Am J Obstet Gynecol. 1992 Jan;166(1 Pt 1):111-6. PMID:1733179

32. Bhattacharya $S$, Bhattacharya $S$. Effect of miscarriage on future pregnancies. Womens Health. 2009;5(1):5-8 (http://www. futuremedicine.com/doi/pdf/10.2217/17455057.5.1.5).

33. Population Council. Report on induced abortions and unintended pregnancies in Pakistan, 2012 (http://www.popcouncil.org/uploads/pdfs/2014RH_PostabortionCare_Pakistan. pdf, accessed 25 May 2017).

34. Mumbare SS, Maindarkar G, Darade R, Yengl S, Tolani MK, Patole K. Maternal risk factors associated with term low birth weight neonates: a matched-pair case control study. Indian Pediatr. 2012 Jan;49(1):25-8. PMID:21719926

35. Demelash H, Motbainor A, Nigatu D, Gashaw K, Melese A. Risk factors for low birth weight in Bale zone hospitals, South-East Ethiopia: a case-control study. BMC Pregnancy Childbirth. 2015;15:264 (https://bmcpregnancychildbirth.biomedcentral. com/articles/10.1186/s12884-015-0677-y).

36. Bhaskar RK, Deo KK, Neupane U, Chaudhary Bhaskar S, Yadav BK, Pokharel HP, et al. A Case Control Study on Risk Factors Associated with Low Birth Weight Babies in Eastern Nepal. Int J Pediatr. 2015

37. Balarajan Y, Subramanian SV, Fawzi WW. Maternal iron and folic acid supplementation is associated with lower risk of low birth weight in India. J Nutr. 2013 Aug;143(8):1309-15. PMID:23761647

38. Stoltzfus RJ, Mullany L, Black RE. Iron deficiency anaemia. In: Comparative quantification of health risks: global and regional burden of disease attribution to selected major risk factors. Geneva: World Health Organization; 2004 (http://www.who. int/publications/cra/chapters/volume1/0163-0210.pdf?ua=1, accessed 25 May 2017).

39. Allen LH. Biological mechanisms that might underlie iron's effects on fetal growth and preterm birth. J Nutr. 2001 Feb;131(2S2):581S-9S. PMID:11160591
40. Pasricha SR, Drakesmith H, Black J, Hipgrave D, Biggs BA. Control of iron deficiency anemia in low-and middle-income countries. Blood. 2013 Apr;121(14):2607-17. PMID:23355536

41. Sananpanichkul P, Rujirabanjerd S. Association between maternal body mass index and weight gain with low birth weight in Eastern Thailand. Southeast Asian J Trop Med Public Health. 2015 Nov;46(6):1085-91. PMID:26867367

42. Pan Y, Zhang S, Wang Q, Shen H, Zhang Y, Li Y, et al. Investigating the association between pre-pregnancy body mass index and adverse pregnancy outcomes: a large cohort study of 536 098 Chinese pregnant women in rural China. BMJ Open. 2016 Jul 20;6(6):e011227. PMID:27439613

43. Abu-Saad K, Fraser D. Maternal nutrition and birth outcomes. Epidemiol Rev. 2010;32:5-25. PMID:20237078

44. Odell CD, Kotelchuck M, Chetty VK, Fowler J, Stubblefield PG, Orejuela $\mathrm{M}$, et al. Maternal hypertension as a risk factor for low birth weight infants: comparison of Haitian and African-American women. Matern Child Health J. 2006 Jan;10(1):39-46. PMID:16397832

45. Rahman LA, Hairi NN, Salleh N. Association between pregnancy induced hypertension and low birth weight; a population based case-control study. Asia Pac J Public Health. 2008;20(2):152-8. PMID:19124309

46. Xiong X, Demianczuk NN, Saunders LD, Wang FL, Fraser WD. Impact of preeclampsia and gestational hypertension on birth weight by gestational age. Am J Epidemiol. 2002 Feb 1;155(3):203-9. PMID:11821244

47. Korejo R, Bhutta S, Noorani KJ, Bhutta ZA. An audit and trends of perinatal mortality at the Jinnah Postgraduate Medical Centre, Karachi. J Pak Med Assoc. 2007 Apr;57(4):168-72. PMID:17489521

48. WHORecommendationsforthepreventionandtreatmentofpreeclampsia and eclampsia. Geneva: WHO; 2011. (http://apps. who.int/iris/bitstream/10665/44703/1/9789241548335_eng. pdf, accessed 25 May 2017). 